difficult. Much could be done to popularize the less common species of fish as food: the authors emphasize that only a very few types of fish are to-day widely exploited by commercial fisheries.

Overfishing, a very real problem in certain areas like the North Sea, is given scant attention in this book; and while it is no doubt true that the total production of fish, if it could be exploited, would more than suffice for man's requirements, much of it is not available either because it is in the deep oceans where existing fishing methods are unsuitable, or it is too remote from centres of human population to be harvested economically. Fisheries research has much to contribute to the problem; the sea may be inexhaustible, but is exploitation of the sea on the scale envisaged worth while? Cultivation of the vast barren and desert areas on land would seem to be a more direct and rewarding answer. This book, originally published in the United States, is attractively produced, and is illustrated by some excellent black-and-white photographs. NormaN Houme

\section{THEORY OF THE SOLID STATE}

\section{Quantum Theory of Solids}

By Prof. R. E. Peierls. (International Series of Monographs on Physies.) Pp. viii + 229. (Oxford : Clarendon Press ; London : Oxford University Press, 1955.) 30s. net.

AOUT twenty years ago when the application of A wave mechanics to the theory of the solid state had been investigated in some detail, it appeared that basically all relevant problems except superconductivity had been solved. This stage of the theory bears its fruit now in connexion with many important applications. Many aspects of theory itself based on the earlier pioneer work are being developed at present in minute details. Much of this work, unfortunately, does not appreciate that the theory in its present stage is based on a number of assumptions, and that it has not been possible, so far, to justify all these assumptions in a satisfactory way. It is for this reason that recently a renewed interest in the basic side of the theory of solids has arisen. The difficulties which one faces in this connexion are typical for systems of very many degrees of freedom and are similar to some of the difficulties met in other branches of physics.

In these circumstances it is desirable to have a book which describes the present development of the theory in a simple way without going into too great details, but which clearly points to the assumptions on which the present theory is based. R. E. Peierls's recent monograph fulfils these requirements in an excellent way. The book is divided into eleven chapters, the first three of which deal with atomic vibrations and related processes, whereas the remaining eight chapters are devoted to properties of electrons. A number of subjects, in particular those connected with mechanical and electric strength and with crystal structures, have been omitted from the book; but most of the other important questions are treated, though not all in equal detail. This was necessary in order to restrict the size of the book to about two hundred pages, and the choice of the branches which are treated in some detail must naturally depend on the interest the author has taken in their development. Thus, general questions of electrons in perfect lattices, transport (including heat conduction) and magnetic phenomena are presented more thoroughly than questions of cohesive forces or of the interaction of electrons with light. Even so, the author has found space to impress on the reader the importance of certain effects which are often ignored. This holds, for example, of correlation between electrons, the possible significance of which for optical properties is mentioned, though this has never been properly investigated in the literature. A separate chapter deals with the recent attempts to solve the problem of superconductivity on the basis of the interactions of electrons and lattice vibrations. Both the early success and the later difficulties of this theory are well presented. Recent work on socalled plasma oscillations, which one hopes will help in the treatment of the Coulomb interaction between electrons, has not been included in the book.

The book is mainly addressed to theoretical physicists in so far as it assumes knowledge of the basic methods of quantum mechanics. However, the mathematical treatment is very simple in most chapters, so that the book can be read with profit by the experimentalist who wishes to be instructed on the basis of the models which he is accustomed to use. It is hoped that the book will find a wide circulation, and perhaps sometimes will induce research workers to think before embarking on vast calculations.

H. FRÖHIICH

\section{HIGH-SPEED AERODYNAMICS}

\section{General Theory of High Speed. Aerodynamics}

Edited by W. R. Sears. (High Speed Aerodynamics and Jet Propulsion-Vol. 6.) Pp. xiv +758 . (Princeton, N.J.: Princeton University Press; London: Oxford University Press, 1955.) 100s. net.

THE present work is Vol. 6 in an ambitious 1 project published by the Princeton University Press in the United States and by the Oxford University Press in Britain under the general title of "High Speed Aerodynamics and Jet Propulsion". The whole work is to be completed in twelve volumes and is to cover the related fields of gas dynamics, aerodynamics, combustion and jet propulsion. The editorial board which is responsible for the general supervision of this work consists of Theodore von Kármán, Hugh L. Dryden and Hugh S. Taylor. The work has been in progress for some years and, in fact, the formal establishment of the Aeronautics Publication Program took place at Princeton University in the autumn of 1949 . In this connexion it may be as well to mention one minor criticism of this great and important work, namely, it is sometimes a little difficult to determine the date on which the different contributions to this volume were completed, and therefore difficult to know exactly how recent is the information which is presented. Another comment which is suggested by the fact that this volume, numbered 6 in the series, is the first to be published, is that the present volume is not self-contained and there are references to work which is to be published in Vol. 3 ; for example, Crocco's stream function is referred to in the present volume, but the reader is referred to Vol. 3 for a formal definition of this important concept. Questions of priority of publication and discovery are not considered in this troatise, which indeed makes no pretence of being absolutely complete. Considerations of space themselves have set an inevitable limit to the amount of work which is included. 